\title{
A systematic review of global surgery partnerships and a proposed framework for sustainability
}

\author{
Nicole Jedrzejko, MD \\ Joseph Margolick, MD \\ Jenny Hoang Nguyen, BHSc \\ Maylynn Ding, BHSc \\ Phyllis Kisa, MBChB, MMed \\ Elenor Ball-Banting, BA, PGCert \\ S. Morad Hameed, MD, MPH \\ Emilie Joos, MD CM
}

Presented at the Bethune Roundtable in Global Surgery, May 25-27, 2018, Toronto, Ont., and the Canadian Surgery Forum, Sept. 14-16, 2017, Victoria, B.C.

Accepted May 28, 2020

\author{
Correspondence to: \\ E. Joos \\ Trauma Services \\ Vancouver General Hospital \\ 855 West 12th Ave \\ Vancouver BC V5Z 1M9 \\ emilie.joos@vch.ca
}

DOI: $10.1503 /$ cjs.010719
Background: Building surgical capacity through global surgery partnerships (GSPs) between high and low- and middle-income countries (LMICs) is a rising global health focus. Our aim was to conduct a systematic review to characterize strategies employed by GSPs to build capacity and promote sustainability and to propose a novel reproducible model for sustainability.

Methods: We conducted a systematic review according to the Preferred Reporting Items for Systematic Reviews and Meta-Analyses (PRISMA) statement. We searched PubMed, EMBASE, Medline and African Journals Online to identify all peerreviewed articles published between 2000 and 2016 that described GSPs between partners from the United States or Canada or both and partners from LMICs. We excluded papers that described nonsurgical GSPs, unilateral GSPs (e.g., humanitarian missions) or military initiatives. Descriptive features were analyzed, with a focus on attributes that promote sustainability. We then proposed criteria for sustainability on the basis of the themes that emerged from our review.

Results: Our search retrieved 3580 abstracts, which were then independently reviewed by 4 authors. A total of 128 papers (3.6\%) met the inclusion criteria. They described GSPs in 68 countries on 5 continents. Among the GSPs, 21.9\% demonstrated community engagement and $51.6 \%$ included multidisciplinary collaboration. Surgical training or education was provided in $81.3 \%$ of GSPs. Although $64.8 \%$ of GSPs collected data, only $53.1 \%$ reported project-related outcomes. A total of $55.5 \%$ had bilateral authorship for publications, and $28.9 \%$ had multisource funding. Only 1 GSP fulfilled all 6 of our criteria for sustainability.

Conclusion: In this systematic review we identified 6 pillars that are indicators of sustainability: community engagement, multidisciplinary collaboration, education and training, outcomes reporting, bilateral authorship and multisource funding. We propose that future GSPs should build on a foundation of bilateral ideas and expertise exchange, that they should have defined and measurable objectives, that they should engage in continuous evaluation of program outcomes and that they should take a thoughtful and transparent approach to sustained capacity building.

Contexte : Le renforcement de la capacité chirurgicale au moyen de partenariats internationaux en chirurgie (PIC) entre les pays à revenu élevé et ceux à revenu faible ou intermédiaire (PRFI) prend de plus en plus de place en santé mondiale. Nous avons donc réalisé une revue systématique pour caractériser les stratégies de renforcement de la capacité et de promotion de la pérennité employées dans le cadre des PIC, ainsi que pour proposer un modèle de pérennité novateur et reproductible.

Méthodes : Pour notre revue systématique, nous avons suivi le modèle Preferred Reporting Items for Systematic Reviews and Meta-Analyses (PRISMA). Nous avons interrogé les bases de données PubMed, Embase, MEDLINE et African Journals Online pour trouver tous les articles évalués par des pairs publiés entre 2000 et 2016 présentant des PIC conclus entre des organismes des États-Unis ou du Canada (ou les 2) et des organismes de PRFI. Nous avons exclu les articles portant sur des partenariats internationaux dans un domaine autre que la chirurgie, les PIC unilatéraux (p. ex., missions humanitaires) et les initiatives militaires. Nous avons analysé les caractéristiques descriptives des partenariats, en particulier les attributs favorisant leur pérennité. Nous avons ensuite proposé des critères de pérennité en fonction des thèmes dégagés dans la revue systématique.

Résultats : Les 3580 résumés recensés lors de la recherche initiale ont été évalués de façon indépendante par 4 auteurs. Au total, 128 articles (3,6\%) répondaient aux critères d'inclusion. Ces articles présentaient des PIC impliquant 68 pays de 5 continents. De ces PIC, 21,9\% comportaient une mobilisation communautaire, et 51,6\%, 
une collaboration multidisciplinaire. Une formation ou un enseignement relatif à la chirurgie était fourni dans $81,3 \%$ des cas. Si $64,8 \%$ des PIC comprenaient une collecte de données, seuls $53,1 \%$ ont produit des rapports sur les issues du projet. En tout, 55,5\% des PIC avaient conclu une entente de paternité bilatérale pour la publication, et $28,9 \%$ avaient bénéficié d'un financement multisource. Un seul PIC répondait aux 6 critères de pérennité établis.

Conclusion : Six indicateurs de pérennité ont été dégagés dans le cadre de cette revue systématique : mobilisation communautaire, collaboration multidisciplinaire, éducation et formation, production de rapports sur les issues, entente de paternité bilatérale et financement multisource. Les futurs PIC devraient reposer sur un échange d'idées et de connaissances, avoir des objectifs définis et mesurables, évaluer sans cesse les issues du programme et adopter une approche réfléchie et transparente quant au renforcement continu de la capacité.

$\mathbf{M}$ ore than 234 million surgical procedures are performed annually for a wide range of severe and highly prevalent conditions, including obstructed labour, congenital anomalies, cancer, diabetic complications, cataracts, hernias and traumatic injuries. ${ }^{1,2}$ However, approximately $75 \%$ of the world's population has access to less than $25 \%$ of surgical procedures. ${ }^{1}$

In 2016, the United Nations (UN) adopted the Sustainable Development Goals, promoting universal health coverage for all (goal 3.8). ${ }^{1,3}$ Almost simultaneously, the Global Surgery 2030 initiative was unveiled by the Lancet Commission on Global Surgery, providing a framework of recommendations, indicators and targets to improve access to surgery. ${ }^{1}$ One of the barriers to delivery of high-quality and effective surgical care is the paucity of surgeons in lower income countries, with a 100-fold difference between countries like Canada and Central African Republic (specialist surgical workforce 36 per 100000 population v. 0.36 per 100000 population). ${ }^{4}$ Improving access to surgery by focusing on specialist workforce density and surgical volumes through sustainable partnerships between high-income countries and low- and middle-income countries (LMICs) may be a way to build capacity.

In 2015, a systematic review led by North American, British and African academic institution assessed the surgical literature from resource-limited countries. ${ }^{5}$ Among the 2049 included papers, only $67 \%$ of surgical initiatives reported outcomes and only $21 \%$ of publications included an author from an LMIC. The authors of the review recommended augmenting the quality and delivery of surgical care by developing research strategies in centres of excellence, building partnerships and focusing on outcome-directed research. ${ }^{5}$ To our knowledge, no additional systematic reviews or meta-analyses have been conducted describing global surgical collaborations since the inception of the 2015 Sustainable Development Goals.

To reach the ambitious target of $80 \%$ coverage for essential surgical services worldwide by 2030 , set by the Lancet Commission and endorsed by World Health Assembly 2015 resolution 68.31 ("strengthening emergency and essential surgical care and anesthesia as a component of universal health coverage"), global surgery partnerships (GSPs) must be both comprehensive and sustainable. ${ }^{1,3}$ However, sustainability in global surgery is difficult to define, and the literature has not yet created a standardized and reproducible definition of sustainability. Our objectives were to quantify and describe all published GSPs between the United States or Canada (or both) and LMIC institutions and to propose a novel reproducible model for sustainability.

\section{Methods}

This systematic review used the methodology established by the Preferred Reporting Items for Systematic Reviews and Meta-Analyses (PRISMA) group with adherence to literature search criteria. ${ }^{6}$ The PubMed, EMBASE, Medline and African Journals Online databases were searched using the following initial search terms: (surgery) and (low- and middle-income countr[ies]) and (partnership, cooperation, initiative, collaboration, education) over a 16-year period from 2000 to 2016. The abstracts retrieved in the initial search were then independently screened by 4 authors (N.J., J.N., M.D. and E.J.) to determine their eligibility for full-text descriptive analysis. Data collection variables included publication demographics (i.e., year, journal, partners, countri[es] involved, study type), degree of collaboration (i.e., surgical specialties involved, multidisciplinary collaborators), partnership type (e.g., academic, civil society, government) and GSP characteristics.

To be eligible for inclusion, papers had to describe partnerships between at least 1 institution from the US or Canada and at least 1 institution from LMICs, classified as such by the World Bank as countries with gross national income per capita of US\$4085 or less as of February 2012.7 Surgical care (including each surgical subspecialty, surgical obstetrics and gynecology, and anesthesia) was the main focus of each GSP. We excluded GSPs not meeting these definitions, nonsurgical initiatives (e.g., obstetricians working exclusively in family planning), unilateral initiatives 
(e.g., short-term disaster or humanitarian relief programs, charitable organizations run by North American participants) and initiatives run or funded by military organizations. Data from the papers that met the inclusion criteria were recorded and descriptively summarized in numeric and graphic Excel forms.

\section{Results}

\section{Descriptive variables}

Our initial search identified 3580 abstracts; 128 papers $(3.6 \%)$ met the inclusion criteria (Figure 1). The most common article type was case reports $(n=68,53.1 \%)$, followed by retrospective chart reviews $(n=14,10.9 \%)$, surveys $(n=10,7.8 \%)$ and editorials, letters or commentaries $(n=10,7.8 \%)$ (Table 1). The majority of the GSPs $(n=94,73.4 \%)$ originated in the US, 24 originated in Canada, and 10 were a collaboration between the 2 countries (Figure 2).

Overall, 68 countries on 5 continents were represented. The country with the most GSPs was Uganda $(n=18)$, followed by Haiti $(n=$ $13)$, Kenya $(n=12)$, Tanzania $(n=10)$, Vietnam $(n=10)$ and India $(n=10)$ (Figure 3). Although general surgery and trauma was the most represented specialty $(n=61,47.7 \%)$, $77.3 \%$ of GSPs included other subspecialties such as orthopedics $(n=31,24.2 \%)$, obstetrics and gynecology $(n=18,14.1 \%)$, plastics $(n=$ $17,13.3 \%)$, neurosurgery $(n=16,12.5 \%)$, anesthesia $(n=12,9.4 \%)$, otolaryngology $(n=$ $11,8.6 \%)$, urology $(n=13,10.2 \%)$, ophthalmology $(n=7,5.5 \%)$, cardiothoracic surgery $(n=4,3.1 \%)$ and dentistry and oral maxillofacial surgery $(n=3,2.34)$. The duration of projects varied from 2 weeks to 40 years. All GSPs involved a collaboration between either a US or Canadian academic institution (or both) $(n=119,93.0 \%)$ and a LMIC academic institution $(n=$ $95,74.2 \%)$, civil society organization $(n=58,45.3 \%)$ or governmental institution $(n=67,52.3 \%)$.

\section{Development of the pillars of sustainability}

Our review of GSPs for features of sustainability revealed 6 recurring themes, which we termed the pillars of sustainability. We defined these themes in collaboration with the University of British Columbia Branch for International Surgical Care.

The first pillar is community engagment. GSPs that exhibited community engagement had a partnership with a
Records identified in PubMed, EMBASE, Medline, African Journals Online databases from 2000 to 2016 $n=3192$
Additional records identified through reference mining $n=388$
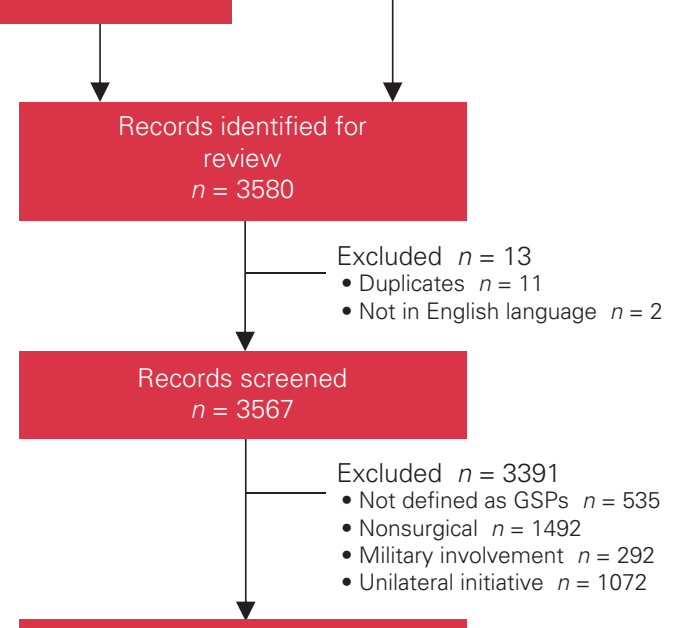

Full-text articles assessed for eligibility $n=176$
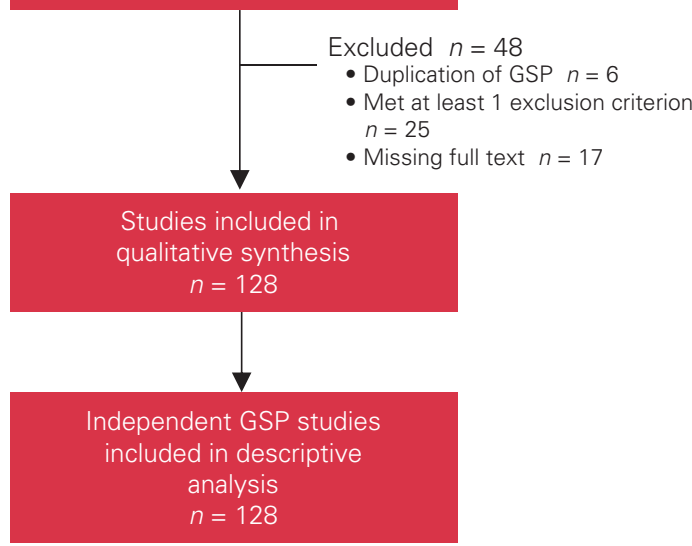

Studies included in qualitative synthesis $n=128$

ndependent GSP studies cluded in descriptive

Fig. 1. PRISMA flowchart. GSP = global surgery partnership.

Table 1. Publications on global surgery partnerships included in the systematic review

\begin{tabular}{|lc|}
\hline Type & No. (\%) of publications \\
\hline Case study & $1(0.8)$ \\
\hline Case control & $2(1.6)$ \\
\hline Cost-effectiveness analysis & $1(0.8)$ \\
\hline Descriptive analysis & $3(2.3)$ \\
\hline Editorial, letter or commentary & $10(7.8)$ \\
\hline Lecture or poster & $1(0.8)$ \\
\hline Medical device trial & $4(3.1)$ \\
\hline Prospective cohort & $5(3.9)$ \\
\hline Prospective observational & $2(1.6)$ \\
\hline Qualitative analysis & $1(0.8)$ \\
\hline Quality improvement & $1(0.8)$ \\
\hline Survey & $10(7.8)$ \\
\hline Case report & $68(53.1)$ \\
\hline Retrospective chart review & $14(10.9)$ \\
\hline Retrospective cohort & $5(3.9)$ \\
\hline
\end{tabular}




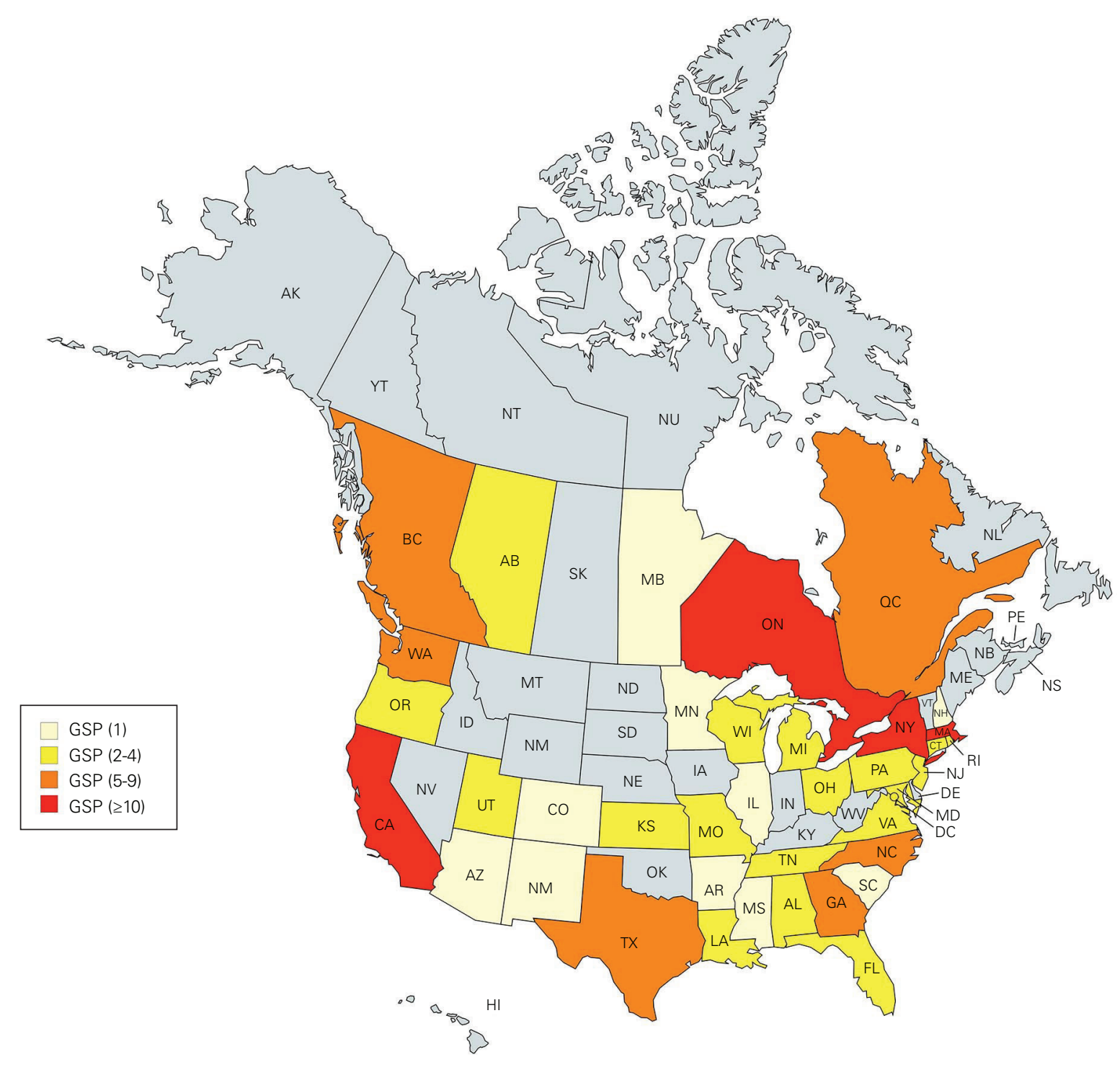

Fig. 2. Heat map of the American states and Canadian provinces in which the offices of the GSPs were located. GSP = global surgery partenrship.

governmental institution (e.g., ministry of health, district hospital), or there was a nonacademic active community member participating in the initiative (e.g., village chief, religious leader, patient groups).

The second pillar is multidisciplinary collaboration. In projects exhibiting this pillar, nonsurgeon health care professionals played a role in surgical care (e.g., nonsurgeon physicians, medical learners, nurses, other allied health professionals).

The third pillar is education and training, which comprises any structured or unstructured teaching. Structured teaching included support to undergraduate or postgraduate surgical programs, formal accredited courses and workshops for practising surgeons, and surgical camps. Unstructured teaching was defined as informal visits by surgeons to the partner country and mentorship.

The fourth pillar is outcome measurement. We included in this category any paper that involved data collection with the goal of measuring outcomes (e.g., evaluation of intervention or operator performance, educational assessment, evaluation of clinical or patient outcomes).

The fifth pillar is bilateral authorship. We included in this category papers that had at least 1 individual from the host LMIC institution in the author list.

The sixth pillar is multisource funding. This included projects with any type of funding (e.g., grants, donations) 


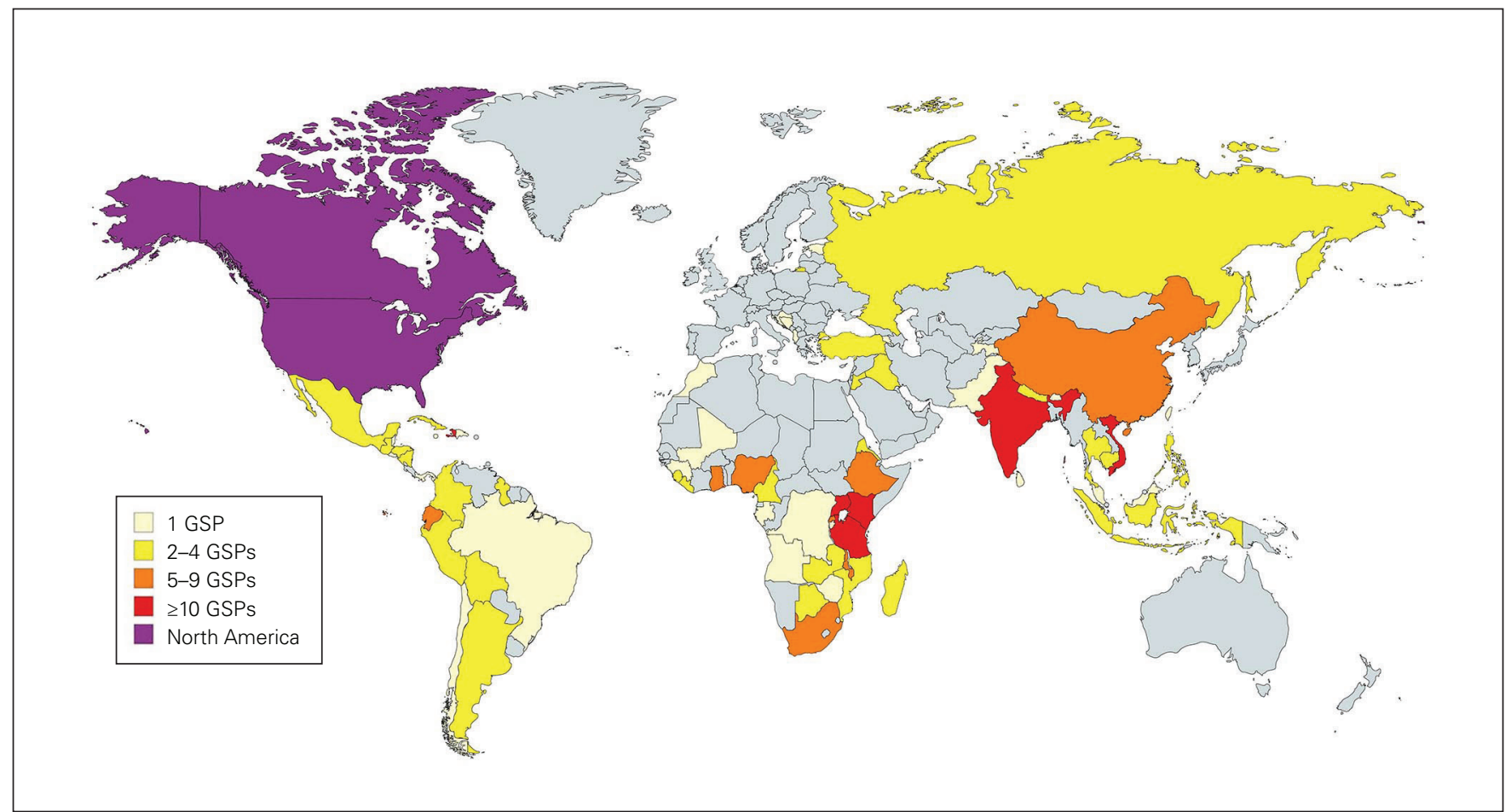

Fig. 3. Heat map of the locations of the institutions in low- and middle-income countries that partnered with North American institutions in GSPs. GSP = global surgery partenrship.

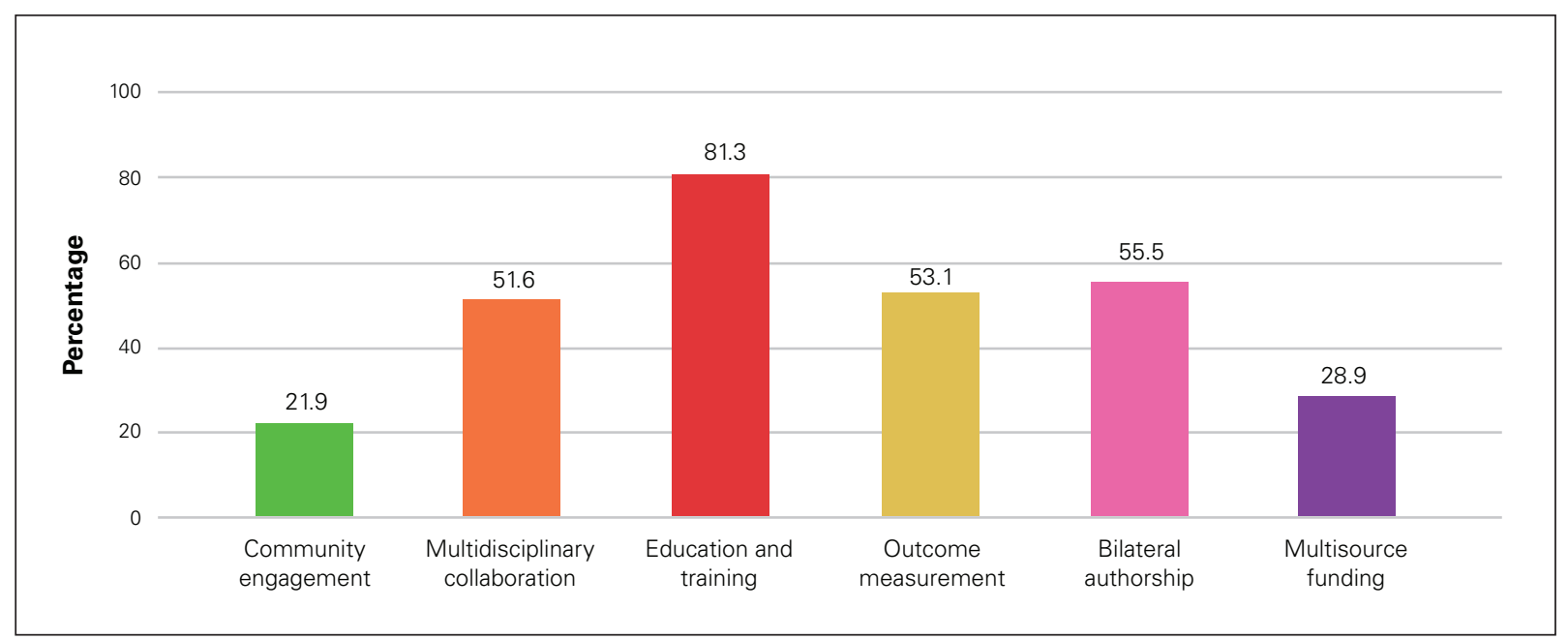

Fig. 4. Frequencies with which sustainability criteria were met by 128 publications on global surgery partnerships between 2000 and 2016 .

that originated from more than a single funding source (academic centres, foundations, government or ministry, individual contributions) to cover direct costs (i.e., staff salaries, resources, overhead) and indirect costs (i.e., time, physical space, missed opportunity costs) associated with the GSP.

We categorized the GSPs that met the study inclusion criteria within these 6 pillars of sustainability (Figure 4). A total of $21.9 \%$ of GSPs explicitly mentioned community engagement. Multidisciplinary collaboration was present in $51.6 \%$ of GSPs, with 66 papers describing involvement of nonsurgical health care professionals. Out of all GSPs, 35.9\% involved nonsurgeon physicians, $25.8 \%$ involved medical trainees (i.e., residents, fellows), $39.1 \%$ involved nursing staff and $27.3 \%$ involved other allied health professionals (e.g., physiotherapists, social workers). The majority of the GSPs (81.3\%) offered education and training as part of their initiative, and most training programs were directed to LMIC health care professionals (71.9\%). Five GSPs $(3.9 \%)$ contributed to curriculum development for a formal residency program or supported an existing accredited residency program. ${ }^{8-12}$ 
Although $64.8 \%$ of projects collected data, only $53.1 \%$ reported outcomes and $29.0 \%$ included quality improvement metrics. When outcomes were measured, the focus was mainly on intervention evaluation (37.5\%), then patient outcomes $(27.3 \%)$, educational outcomes $(25.0 \%)$ and operator performance (19.5\%). A total of $35.2 \%$ of all GSPs included a formal needs assessment. Just over half $(55.5 \%)$ had bilateral authorship in their publication. Almost half $(46.1 \%)$ mentioned a funding source, with just $28.9 \%$ of GSPs demonstrating multisource funding and $12.5 \%$ evaluating the cost-effectiveness of their partnership or intervention.

\section{The 6 pillars illustrated}

Only 1 GSP met the criteria for all 6 pillars of sustainability: Emory University's Global Surgery Program. ${ }^{10}$ The authors, including Dr. Ronald Tubasiime representing the Soddo Christian Hospital in Ethiopia, describe a 20-year partnership between Emory and Addis Ababa University, benefiting from multisource funding from the US Agency for International Development and the Carter Center. Their GSP focused on improving surgical outcomes through multidisciplinary collaborations with the departments of medicine, pediatrics, radiology, obstetrics and gynecology, pathology and surgery. The support of the international partners in running a 5-year general surgery residency program out of Soddo Christian Hospital and Myungsung Christian Medical Center has led to a bilateral exchange of trainees and multiple research initiatives (e.g., trauma and oncology patient registry).

Several GSPs demonstrated individual pillars. Below, we highlight 1 study to illustrate each of the pillars.

\section{Community engagement}

The International Federation of Gynecology and Obstetrics's Save the Mothers Initiative aims to increase the availability of and access to emergency obstetrical care in rural Uganda. A thorough needs assessment was performed, drawing data from national health surveys, multiple stakeholder dialogues and community focus groups conducted by the Department of Women and Gender Studies at Makerere University in collaboration with McMaster University in Hamilton, Ontario, Canada. The project's implementation included recruitment and training of local midwives, negotiations with Ministry of Health officials and hospital administrators plus workshop development by members of the Department of Women and Gender Studies. ${ }^{13}$

\section{Multidisciplinary collaboration}

A paper on the Human Islet Isolation Laboratory at the Catholic University of Paraná, Curitiba, Brazil, describes the creation of their first pancreatic islet transplantation program with academic and operational support from the
University of Alberta and University of Miami, illustrating a North American institutional partnership. The initiative involved training local surgeons, endocrinologists, nephrologists and technicians in perioperative transplantation care. ${ }^{14}$

\section{Education and training}

A pediatric surgery fellowship exchange program between Montreal Children's Hospital in Montreal, Canada, and Bethany Kids of Kijabe Hospital in Kenya underwent a formal evaluation. Retrospective case $\log$ reviews and quantitative survey data revealed substantial gains for fellows from both institutions. Despite the differences in health care environments and surgical scope between the 2 training centres, fellows from both sites gained exposure to a diversity of cases only available through this collaboration, highlighting the reciprocal advantages of education-based global programs. ${ }^{15}$

\section{Outcome measurement}

A collaboration between Neiva University Hospital in Colombia and the University of Pittsburgh in Pennsylvania studied the implementation of a standardized trauma protocol (STP) with a focus on the influence of the STP on the outcomes of patients with traumatic brain injuries. Data collection was difficult because of limited electronic health records; however, through an electronic database used for hospital finances, the authors were able to collect demographic and procedure data. Implementation of the STP reduced in-hospital mortality of patients with traumatic brain injuries by 4 -fold. The results of this study encouraged subsequent dissemination of STPs throughout sister sites in Latin America. ${ }^{16}$

\section{Bilateral authorship}

A review article described surgical research partnerships between Universidade Eduardo Mondlane in Mozambique and the University of California San Diego with the goal of building robust foundations of data and evidence for future initiatives. A multidisciplinary research team with representatives from both institutions spearheaded a variety of research projects aiming to assess surgical disease burden in rural Mozambique, with balanced representation from the 2 institutions in the author list (4 authors from the University of California San Diego and 3 from Universidade Eduardo Mondlane). ${ }^{17}$

\section{Multisource funding}

A report on the Orthopaedic Trauma Care Specialist (OTCS) residency program based in Haiti in collaboration with the University of Maryland and McMaster University described multisource funding from the Haitian government, nongovernmental hospital organizations and research grants through the Canadian Institutes 
of Health Research, the Michael Smith Foundation for Health Research and the Vancouver Coastal Health Research Institute. A cost-effectiveness investigation justified the cost of \$US2.5 million per year over the program's 5-year implementation in terms of \$US200 per disability-adjusted life year averted, supporting Haiti's investment in the OTCS as an economic strategy to mitigate the disease burden of orthopedic trauma. ${ }^{12}$

\section{Discussion}

Although surgical missions or "surgical volunteerism" that provide direct service delivery were frequent in past decades, we are now seeing a proliferation of organized, structured partnerships between well-established academic institutions and LMICs. ${ }^{18}$ However, multiplication of initiatives can lead to duplication of efforts, redundancy, inefficiency and partner fatigue. For example, 3 of the 128 GSPs included in our study focused on developing laparoscopic skills for general surgery residents in Kenya. ${ }^{19-21}$ Today's global surgical care movement is essentially a universal humanitarian response to a chronic crisis: lack of access to surgical care for 5 billion people. ${ }^{1}$ Although actors responding to humanitarian crises (e.g., Red Cross and Red Crescent, Médecins Sans Frontières) benefit from coordination mechanisms at the level of the United Nations Office for the Coordination for Humanitarian Affairs and have to adhere to strict quality criteria under the World Health Organization's Emergency Medical Teams Initiative, the academic response remains largely uncoordinated without official quality control. ${ }^{22}$

The global surgery community wants to support LMICs in improving surgical care, believing that if expertise, skills and efforts are combined from multiple sources, we can prevent unnecessary deaths from surgical conditions. What we need to achieve to reach this goal has been established by the Lancet Commission on Global Surgery on the basis of 6 quality indicators for universal access to safe, affordable surgical and anesthetic care. ${ }^{1}$ To achieve this goal, the commission also articulates a highlevel framework for building sustainable and well-performing surgical systems in partnerships between well-resourced academic institutions and clinicians in low-resource settings. ${ }^{1}$
The ethics of GSPs have recently been scrutinized by the American Surgical Association Working Group on Global Surgery. In a statement on effective involvement of the US academic surgical community in LMICs, the working group emphasized criteria for successful partnerships similar to the pillars in our study, including understanding priorities defined by local institutions (corresponding to our community engagement pillar), curriculum development (corresponding to our education and training pillar), development of measures of success (corresponding to our outcome measurement) and reinforcing an ethical relationship between 2 partners (corresponding to our bilateral authorship pillar ). ${ }^{23}$ However, neither the Lancet Commission on Global Surgery nor the American Surgical Association Working Group provide a practical guide on how to develop sustainable and high-quality partnerships.

We consider each of the 6 pillars identified in this systematic review as an indicator of sustainability, with a target of $100 \%$ adherence for GSPs. Our results suggest that North American GSPs are below target for all of the indicators.

We hereby propose the following framework for sustainable GSPs (Figure 5). We believe that community engagement is essential and that it is the first pillar of sustainability, as demonstrated in the recent Ebola epidemics, where the most effective and efficient containment measures were achieved in communities whose voices were heard by global health governance. ${ }^{24,25} \mathrm{We}$ recommend the formalization of this pillar into a memorandum of understanding, to be signed by both partner institutions, so that

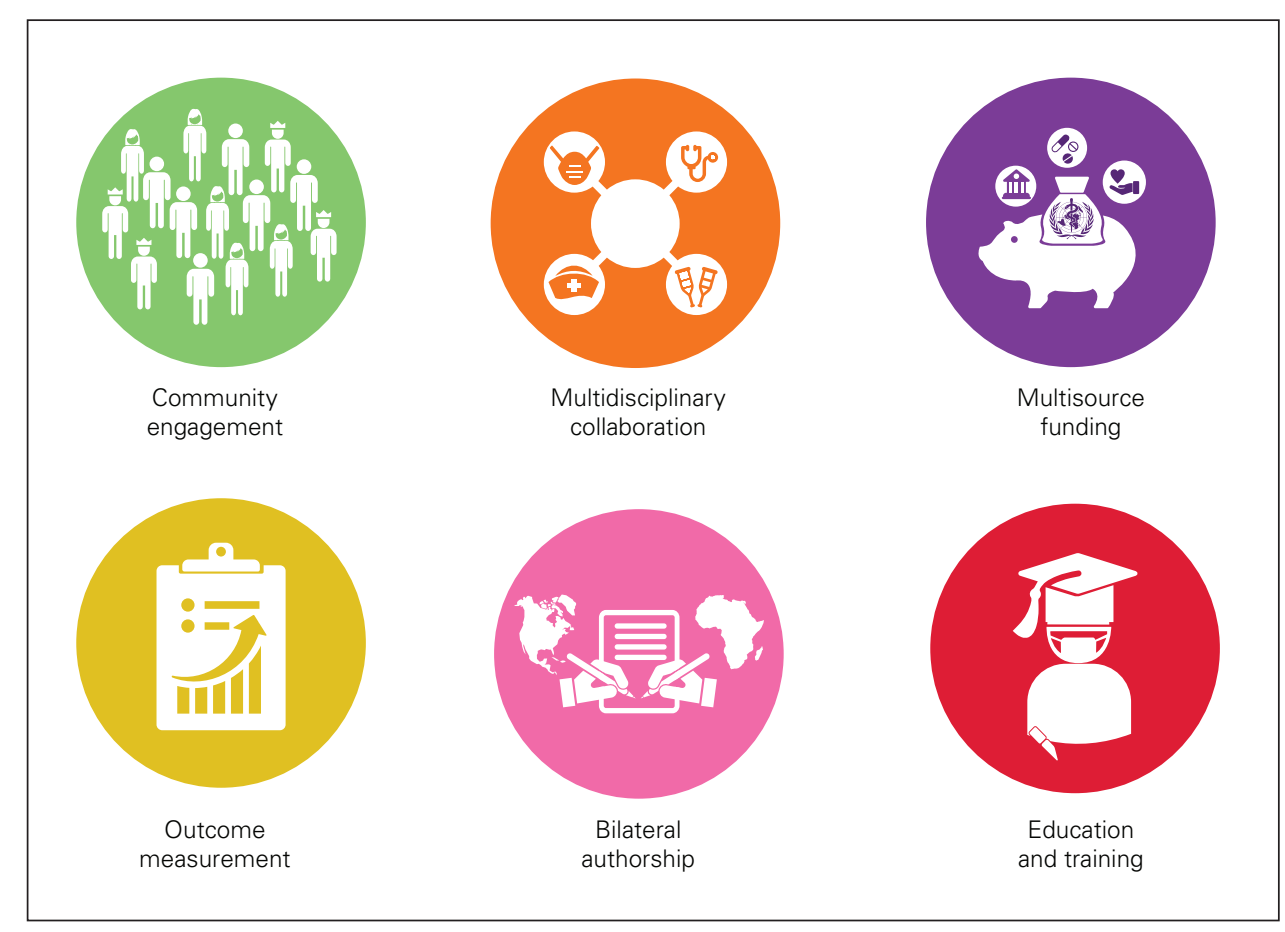

Fig. 5. Proposed 6 pillars of sustainability. 
roles and expectations can be clearly delineated from the beginning of their partnership. This process encourages mutual respect and empowers LMIC partners to include community leaders essential to GSP success.

Once local partners and priorities have been defined, GSPs should aim to involve all actors necessary for their project's success. The Lancet Commission on Global Surgery recognizes that the surgical workforce includes "surgical and anesthetic providers, nurses, pathologists, radiologists, laboratory technicians, [operating] theatre managers, [and] community health workers;" thus, all efforts to build a resilient surgical system should include these specialties. ${ }^{1}$

Beyond offering locally relevant training, GSPs must align with existing local training programs to augment their capacity, with the goal of integrating accredited training bodies such as the College of Surgeons of East, Central and Southern Africa or the West African College of Surgeons. If courses or training programs are offered, they should include local staff and be designed for future repeatable use. For example, the Better and Systematic Trauma Care (BEST) training course in Norway is a simulation-based multidisciplinary trauma course that emphasizes these principles of sustainability and has been associated with long-term improvement in national trauma care. ${ }^{26}$

GSPs need to adapt to local needs with demonstrable beneficial results. As they involve academic global partners with established research infrastructure, GSPs need to perform thorough needs assessments through objective data collection and plan to measure outcomes relevant to local contexts. Progress is often hindered by the lack of good-quality data. We can help build data collection infrastructure by exporting electronic registries applicable to low-resource settings..$^{27,28}$

The culmination of successful academic partnerships is coauthorship in research publications. It is disappointing that some GSPs do not result in published recognition of contributing partners. Bilateral authorship or contribution acknowledgement is a marker of an equitable partnership. LMIC authors should also be encouraged and supported to publish as first authors for publications resulting from their original research ideas.

Funding for personnel and resources in GSPs is a critical limiting factor of sustainability. Projects that depend on single-source funding reflect challenges in obtaining long-term funding. A minority of the GSPs included in this review explicitly described funding sources and only a third cited diverse sources of funding for their activities. Global health governance is becoming more complex and decentralized; the rise of new donors such as philanthropic organizations with special interest in noncommunicable diseases (e.g., Bloomberg Group) and emerging middle-income countries (e.g., Brazil, Russia, India, China) can represent untapped financing opportunities for surgery within the global health funding sphere. ${ }^{29}$

\section{Limitations}

We did not search or include the grey literature in our systematic review. Including searches on Internet publications, the websites of departments of surgery or global surgery offices, and GSPs known to colleagues would be important ways to capture the most comprehensive list of previous and current GSPs from the US and Canada. We chose not to include GSPs in collaboration with, funded by or operated by military organizations or unilateral GSPs functioning independently of LMIC institutions. It is important to note that several military and humanitarian organizations are significant contributors to global surgical care. Finally, a consistent limitation in the evaluation of GSP sustainability is the lack of long-term follow-up; we have not reported the results of an online survey we sent to all corresponding authors of the papers we included in our review because of a poor response rate and the lack of perspectives from host LMIC institutions involved with the GSPs.

\section{Conclusion}

By proposing 6 pillars of GSP sustainability, we hope to facilitate efforts by the academic global surgery community to deliver high-quality surgical care with LMICs. This framework may be implemented in academic global surgery offices as a structured approach for new or ongoing GSPs. We recommend that global surgery offices collaborate to create an efficient and effective network across North America. Organizations such as the American College of Surgeons, the American Surgical Association and the Canadian Association of General Surgeons have active global surgery committees. The infrastructure exists to create a centralized database for all GSPs and a coordinating body that can oversee operations, monitor quality and move us toward the goals for surgical care of the Lancet Commission on Global Surgery by 2030.

Acknowledgements: The authors thank the University of British Columbia (UBC) Branch for International Surgical Care, Dr. Robert Taylor (UBC), Dr. Vanessa Fawcett (University of Alberta) and Dr. Brian Cameron (McMaster University) for their feedback on the six pillars of sustainability.

Affiliations: From the Department of Surgery, Division of General Surgery, University of British Columbia, Vancouver, BC (Jedrzejko, Margolick, Ball-Banting); the Faculty of Medicine, University of Toronto, Toronto, Ont. (Nguyen); the Michael G. DeGroote School of Medicine, McMaster University, Hamilton, Ont. (Ding); the Department of Surgery, Makerere University, Kampala, Uganda (Kisa); and Trauma Services, Vancouver General Hospital, Vancouver, BC (Hameed, Joos).

Competing interests: None declared. 
Contributors: N. Jedrzejko, J. Margolick, M. Ding, P. Kisa, E. Ball-Banting, M. Hameed and E. Joos conceived the study. N. Jedrzejko, J. Margolick, J. Nguyen, M. Ding and E. Joos acquired the data, which N. Jedrzejko, J. Margolick, J. Nguyen, M. Ding, E. BallBanting, M. Hameed and E. Joos analyzed. N. Jedrzejko, M. Ding, P. Kisa and E. Joos wrote the article, which N. Jedrzejko, J. Margolick, J. Nguyen, M. Ding, P. Kisa, E. Ball-Banting, M. Hameed and E. Joos critically revised. All authors agreed to be accountable for all aspects of the work.

Content licence: This is an Open Access article distributed in accordance with the terms of the Creative Commons Attribution (CC BY-NC-ND 4.0) licence, which permits use, distribution and reproduction in any medium, provided that the original publication is properly cited, the use is noncommercial (i.e., research or educational use), and no modifications or adaptations are made. See: https://creativecommons.org/licenses/by-nc-nd/4.0/

\section{References}

1. Meara JG, Leather A, Hagander L, et al. Global surgery 2030: evidence and solutions for achieving health, welfare and economic development. Lancet 2015;386:569-624.

2. World Health Organization. World Health Assembly 68 documentation. Geneva: World Health Organization; 2015. Available: http:// apps.who.int/gb/e/e_wha68.html (accessed 2018 Jul 1).

3. United Nations Department of Economic and Social Affairs. Goal 3: Sustainable Development Knowledge Platform. New York (NY): United Nations; 2015. Available: https://sustainabledevelopment.un. org/sdg3 (accessed 2018 Jul 1).

4. The Lancet Commission on Global Surgery. Global Indicator Initiative. Dataset indicator 2. London (UK): The Lancet Commission on Global Surgery; 2015. Available: www.lancetglobalsurgery.org/ indicators (accessed 2018 Jul 1).

5. Pauyo T, Debas H, Kyamanywa P, et al. Systematic review of surgical literature from resource-limited countries: developing strategies for success. World 7 Surg 2015;39:2173-81.

6. Moher D, Liberati A, Tetzlaff J, et al. Preferred reporting items for systematic reviews and meta-analyses: the PRISMA statement. Int 7 Surg 2010;8:336-41.

7. World Bank. World Bank country and lending groups. Washington (DC): World Bank; 2012. Available: https://datahelpdesk.worldbank. org/knowledgebase/articles/906519-world-bank-country-and-lending -groups (accessed $2018 \mathrm{Jul}$ 1).

8. Bernstein M, Hamstra S, Woodrow S, et al. Needs assessment of neurosurgery trainees: a survey study of two large training programs in the developing and developed worlds. Surg Neurol 2006;66:117-24.

9. Cameron BH, Rambaran M, Sharma D, et al. The development of postgraduate surgical training in Guyana. Can 7 Surg 2010;53:11-6.

10. Love TP, Martin BM, Tubasiime R, et al. Emory global surgery program: learning to serve the underserved well. F Surg Educ 2015;72:e46-51.

11. Rickard J, Ssebuufu R, Kyamanywa P, et al. Scaling up a surgical residency program in Rwanda. East Cent Afr 7 Surg 2016;21:11-23.

12. Slobogean G, Sprague S, Furey A, et al. Orthopaedic trauma care specialist program for developing countries. 7 Orthop Trauma 2015;29:S26-8.
13. Lalonde AB, Okong P, Mugasa A, et al. The FIGO Save the Mothers Initiative: The Uganda-Canada collaboration. Int 7 Gynaecol Obstet 2003;80:204-12.

14. Sotta ED, Madalozzo TM, Percegona L, et al. Establishing an islet transplantation program in a developing country. Transplant Proc 2004;36:1700-3.

15. Baird R, Poenaru D, Ganey M, et al. Partnership in fellowship: comparative analysis of pediatric surgical training and evaluation of a fellow exchange between Canada and Kenya. 7 Pediatr Surg 2016;51:1704-10.

16. Kesinger MR, Nagy L, Sequeira D, et al. A standardized trauma care protocol decreased in-hospital mortality of patients with severe traumatic brain injury at a teaching hospital in a middleincome country. Injury 2014;45:1350-4.

17. Rose J, Bendix P, Funzamo C, et al. Universities form research partnership to improve care in Mozambique. Bull Am Coll Surg 2015;100:27-34.

18. Pezzella AT. Volunteerism and humanitarian efforts in surgery. Curr Probl Surg 2006;43:848-929.

19. MacLeod JB, Okech M, Labib M, et al. Evaluation of trauma and critical care training courses on the knowledge and confidence of participants in Kenya and Zambia. World 7 Surg 2011;35:9-16.

20. Riviello R, Ozgediz D, Hsia R, et al. Role of collaborative academic partnerships in surgical training, education, and provision. World $\mathcal{F}$ Surg 2010;34:459-65.

21. Tarpley M, Hansen E, Tarpley J. Early experience in establishing and evaluating an ACGME-approved international general surgery rotation. 7 Surg Educ 2013;70:709-14.

22. Norton I, von Schreeb J, Aitken P, et al. Classification and minimum standards for foreign medical teams in sudden onset disasters. 1st ed. Geneva: World Health Organization; 2013.

23. Mock C, Debas H, Balch C, et al. Global Surgery: Effective involvement of US academic surgery: report of the American Surgical Association Working Group on Global Surgery. Ann Surg 2018;268:557-63.

24. Kutalek R, Wang S, Fallah M, et al. Ebola interventions: listen to communities. Lancet Glob Health 2015;3:e131.

25. Lamunu M, Lutwama J, Kamugisha J, et al. Containing a haemorrhagic fever epidemic: the Ebola experience in Uganda (October 2000-January 2001). Int 7 Infect Dis 2004;8:27-37.

26. Wisborg T, Brattebø G, Brinchmann-Hansen Å, et al. Effects of nationwide training of multiprofessional trauma teams in Norwegian hospitals. 7 Trauma 2008;64:1613-8.

27. Bouchard B, Bado J, Deckelbaum D, et al. The implementation of an app-based dataset for injury data acquisition in Montevideo, Uruguay. Ann Glob Health 2016;82:319-20.

28. Zargaran E, Spence R, Adolph L, et al. Association between real-time electronic injury surveillance applications and clinical documentation and data acquisition in a South African trauma center. FAMA Surg 2018;153:e180087.

29. Clinton C, Sridhar D. Governing global health: Who runs the world and why? 1st ed. New York: Oxford University Press; 2017. 